\title{
Extra-medullary recurrence of myeloid leukemia as myeloid sarcoma after allogeneic stem cell transplantation: impact of conditioning intensity
}

\author{
Jochen J. Frietsch $\mathbb{D}^{1} \cdot$ Friederike Hunstig $^{1,2} \cdot$ Christoph Wittke $^{3} \cdot$ Christian Junghanss $^{3} \cdot$ Tobias Franiel $^{4}$. \\ Sebastian Scholl ${ }^{1} \cdot$ Andreas Hochhaus $^{1} \cdot$ Inken Hilgendorf $^{1}$
}

Received: 1 April 2020 / Revised: 6 June 2020 / Accepted: 16 June 2020 / Published online: 30 June 2020

(c) The Author(s) 2020. This article is published with open access

\begin{abstract}
Myeloid sarcoma (MS) as a solid extra-medullary (EM) manifestation of acute myeloid leukemia (AML), myeloproliferative or myelodysplastic syndromes is a rare presentation of relapse after allogeneic hematopoietic stem cell transplantation (HSCT). The databases of the Departments of Hematology and Oncology of the University Hospitals of Jena and Rostock were screened for patients aged 18 years or older for onset of MS after HSCT for myeloid malignancies between 2002 and 2019. Nineteen patients with MS were identified, the majority of whom had received reduced-intensity conditioning (RIC). The median onset of MS was 425 days after HSCT and the median overall survival since MS was 234 days. Although MS is associated with a poor prognosis, three patients survived more than two years and one more than 11 years after MS onset. These results indicate that RIC protocols may be associated with a higher risk of EM relapse. Since EM relapse occurred in the presence of Graft-versus-host-disease, these observations also demonstrate the limitations of graft-versus-tumor effects after HSCT. In conclusion, occurrence of MS after HSCT is associated with a poor prognosis, as multimodal curative concepts including intensive chemotherapy and another HSCT are often not viable.
\end{abstract}

\section{Introduction}

Myeloid sarcoma (MS), also known as granulocytic sarcoma or chloroma, is defined as an extra-medullary (EM) and infiltrating tumor mass formation of blasts of one or more myeloid linages and maturating cells. It has been described as developing in isolation and de novo, as

Supplementary information The online version of this article (https:// doi.org/10.1038/s41409-020-0984-4) contains supplementary material, which is available to authorized users.

Jochen J. Frietsch

jochen.frietsch@med.uni-jena.de

1 Klinik für Innere Medizin II, Hämatologie und Internistische Onkologie, Universitätsklinikum Jena, Jena, Germany

2 I. Medizinische Klinik und Poliklinik, Universitätsklinikum Hamburg-Eppendorf, Hamburg, Germany

3 Medizinische Klinik III, Klinik für Hämatologie, Onkologie und Palliativmedizin, Universitätsmedizin Rostock, Rostock, Germany

4 Institut für Diagnostische und Interventionelle Radiologie, Universitätsklinikum Jena, Jena, Germany preceding systemic disease, or as a concomitant manifestation of acute myeloid leukemia (AML), myeloproliferative neoplasms (MPN) including blast phase chronic myeloid leukemia (CML), or myelodysplastic syndromes (MDS) [1-3]. It may also manifest as relapse, especially in recipients of allogeneic hematopoietic stem cell transplantation (HSCT) [2, 4-8]. MS can occur at any site in the body, e.g. in the central nervous system (CNS), skin, soft tissue, bones and testis with a slight preference for male sex [2, 6-9].

As diagnosis is challenging and requires a high level of suspicion, diagnostic workup should include tissue biopsy with immunohistochemistry, immunophenotyping, and genetic and molecular analysis. In addition, for the right selection of therapeutic modalities, bone marrow biopsy should be performed to exclude medullary involvement $[10,11]$. Moreover, additionally performed Positron Emission Tomography and Computer Tomography allows for the evaluation of treatment response, reveals previously unnoticed manifestations, and increases diagnostic accuracy [12].

Although manifestation of MS is a rare event [13], 19 patients presenting with MS as a sign of relapse of primary 
disease after allogeneic HSCT were identified at the University Hospitals Jena and Rostock (Germany) between January 2002 and December 2019. A systematic review of the literature on EM relapse after HSCT and treatment available on PubMed is also provided.

\section{Methods}

\section{Patient selection}

The databases of the Departments of Hematology and Internal Oncology of the University Hospitals Jena and Rostock (Germany) were searched for patients with EM MS and carcinomatous meningitis after HSCT for AML, MPN, CML or MDS, and a retrospective review of individual medical records was performed. None of the patients analyzed had a previous history of MS bevor HSCT. Patients were included if they had histologically proven MS based on WHO criteria forming solid tumor masses [1,3]. Patients with simple tissue infiltrations or effusions were excluded.

\section{Transplantation procedures}

The majority of MS patients $(16 / 19,84.2 \%)$ received a reduced-intensity conditioning (RIC) based on treosulfan (11/ $19,57.1 \%)$ or busulfan $(4 / 19,21.1 \%)$ in combination with fludarabine before undergoing allogenic HSCT [14-16]. The remaining MS patients received myeloablative conditioning (MAC; 2/19, 10.5\%) with 12 Gy total body irradiation (TBI) in combination with cyclophosphamide [17], a nonmyeloablative conditioning (NMAC; 1/19, 5.26\%) with 2 Gy TBI and fludarabine [18], or a sequential regimen of clofarabine, cytarabine, busulfan and cyclophosphamide [19]. Graft-versus-host-disease (GvHD) prophylaxis consisted of cyclosporine A (CSA) in combination with short-term methotrexate (MTX) or mycophenolate mofetil (MMF), and antithymocyte globulin (ATG).

\section{Statistical analysis}

Overall survival was calculated from the date of reinfusion of hematopoietic stem cells $\left(\mathrm{OS}^{\mathrm{HSCT}}\right)$ and from MS onset $\left(\mathrm{OS}^{\mathrm{MS}}\right)$ to date of death. MS free survival (MSFS) was defined as the time between HSCT and the date of histologically confirmed MS onset and only calculated for patients suffering from MS. In cases of repeated HSCTs, survival was calculated from the last HSCT. Differences between the Kaplan-Meier survival curves were evaluated by Log-rank test and those between frequencies of MS by the t-test with Welch's correction. A $P$ value of $<0.05$ was considered statistically significant. All analyses were conducted using GraphPad Prism 8.0.2 (GraphPad Inc.).

\section{Results}

\section{Frequency and patient characteristics}

Between January 1st, 2002 and December 31st, 2019, 307 patients with AML (289 patients with primary and 18 with secondary AML, sAML) underwent allogeneic HSCT at the University Hospital of Jena. The patients received MAC, NMAC, or RIC as follows: 103 (35.6\%), 8 (2.8\%) and 178 (61.6\%) of patients with AML as well as $1(5.6 \%), 0(0 \%)$ and 17 (94.4\%) of patients with sAML, respectively. MS after HSCT occurred in 16/307 (5.21\%) of patients with AML. The total number of patients receiving HSCT was not assessed for the whole time period at the University Hospital of Rostock.

Altogether, 19 patients suffering from MS were identified. Patient characteristics are shown in Table 1. Median age of the 7 male and 12 female patients was 57 years (range: 28-65 years). At the time of HSCT, 14 patients were in first complete remission (CR), 4 in second CR, and 1 had histologically confirmed partial response. The majority of patients, 9/19 (47.4\%), received HSCT from a matchedunrelated (MUD), 7/19 (36.8\%) from a matched-related (MRD) and 3/19 (15.8\%) from a mismatched unrelated (MMUD) donor.

Furthermore, 2/37 (5.41\%) patients with CML and MS after HSCT were identified, but excluded from analysis.

\section{Cytogenetics}

Cytogenetic analysis of bone marrow was available for 18 patients and is given in Table 1. FLT3-LM mutation was confirmed in 4 patients at a high $(\geq 0.5)$ and in 1 patient with a low allelic ratio $(<0.5)$. AML patients were classified with intermediate $(6 / 19,31.6 \%)$ or adverse risk $(12 / 19,63.2 \%)$ according to ELN guidelines [20] (see Table 1). No patient was classified with favorable risk, and one patient was not classifiable, as cytogenetic and molecular genetics were not assessable.

\section{Manifestation of myeloid sarcoma}

The median onset of MS was 425 days after HSCT (MSFS; range: 80-1276 days). 9/19 (47.4\%) relapsed in EM sites only, and 5/19 (26.3\%) relapsed in both EM sites and the bone marrow at the time of MS onset. Three patients (26.3\%) with EM relapse progressed to bone marrow involvement within a median time of 5 months (range: 2-24 months) after MS onset. Two patients sustained EM after medullary relapse ( 6 and 18 months), one of whom had initially achieved CR after medullary relapse using FLT3-inhibition.

The regions and organs affected are summarized in Table 1 and vary from very typical tissues such as skin, 


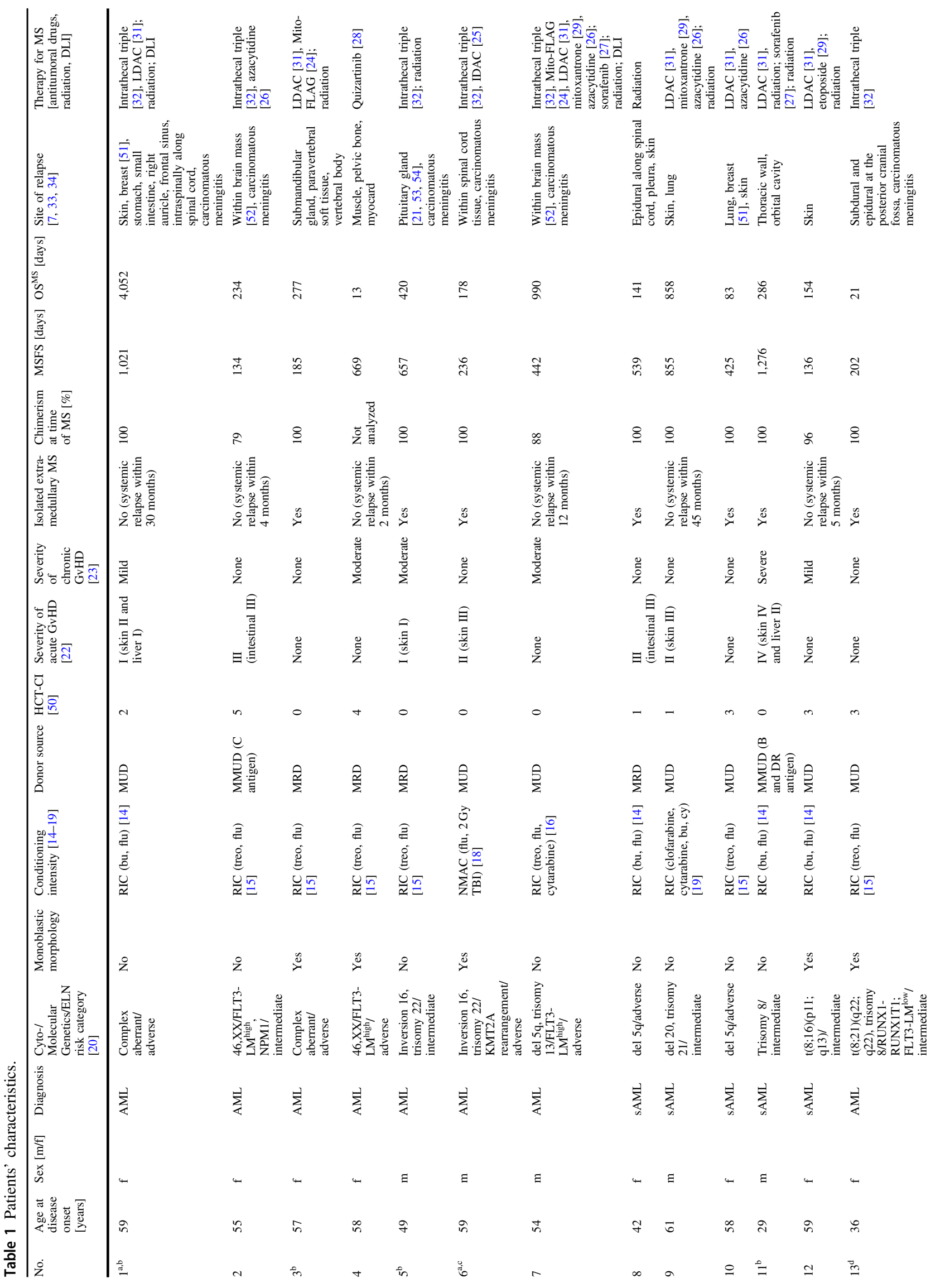




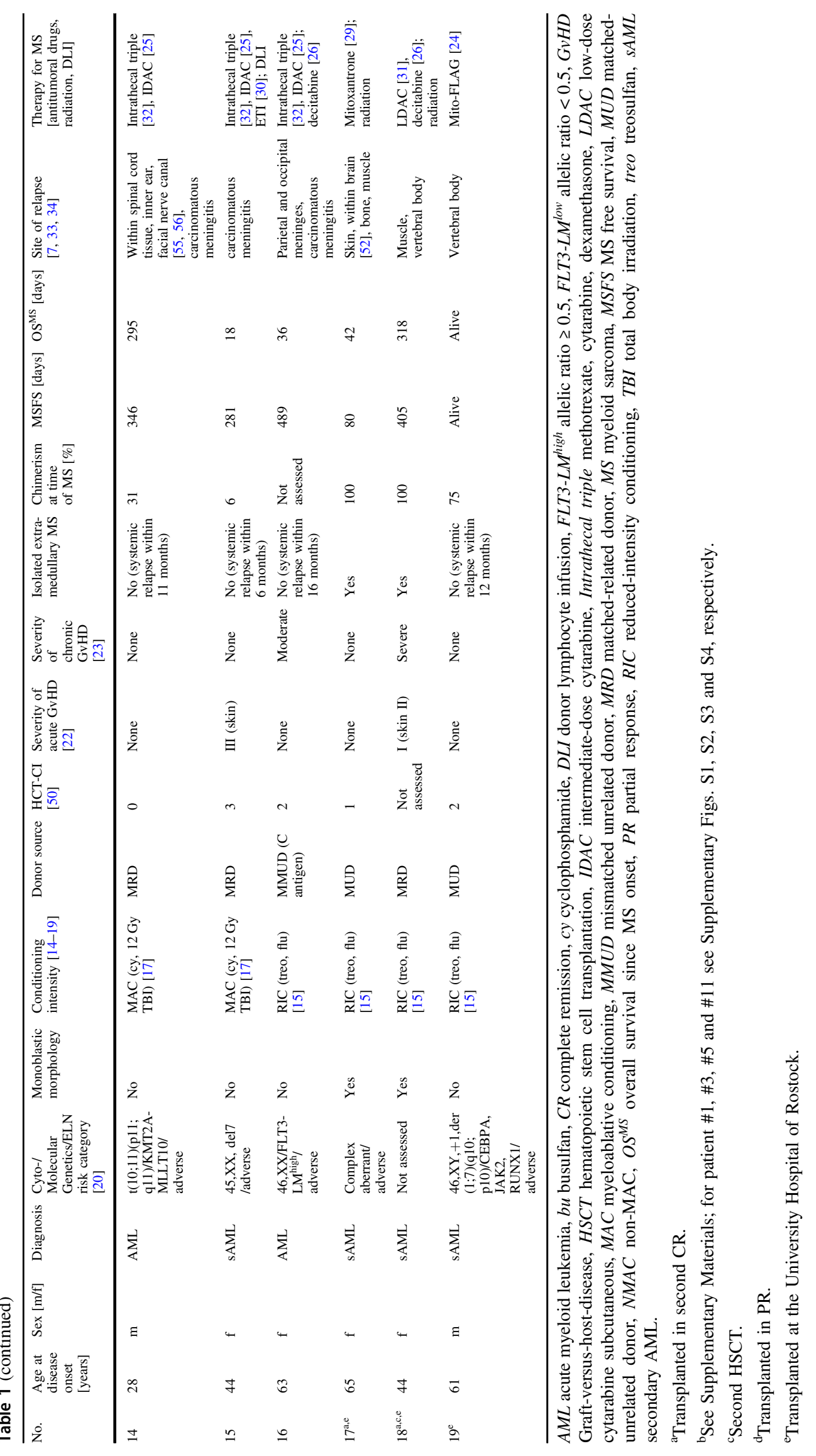


bone or lymph node to extremely rare presentations of MS affecting the pituitary gland [21], breast tissue, eye socket, thoracic wall, atrium, intestine, paranasal sinuses, inner ear, and facial nerve canal. Interestingly, $13 / 19$ (68.4\%) patients developed MS despite a history of GvHD [5 patients with acute, 4 with chronic, and 4 with acute GvHD (aGVHD) becoming chronic/overlap]. Acute and chronic GvHD (cGvHD) was classified according to the criteria of Glucksberg et al. [22] and Filipovich et al. [23], respectively.

\section{Treatment}

MS was treated based on the pattern of leukemic involvement. In case of EM relapse, local applicable anti-tumor treatment methods were used. Local radiotherapy was applied in 11/19 (57.9\%) patients as either the sole treatment modality or in combination. Based on the slow disease kinetics and a drop of chimerism, 3/19 patients (15.8\%) received infusion of donor lymphocytes. Three patients were treated with re-induction therapy with Mito-Flag [24] and four patients with intermediate-dose cytarabine [25]. Six patients received epigenetic therapy $(6 / 19,31.6 \%)[26]$. Two patients with FLT3-LM-positive AML were treated with sorafenib [27] and one with quizartinib [28]. Etoposide and a combination of etoposide, 6-thioguanine, and idarubicine were applied in one case each $[29,30]$. The majority of patients $(14 / 19,73.7 \%)$ received additionally, intermittently or sequentially low-dose cytarabine or mitoxantrone [29, 31]. Nearly half of patients $(9 / 19,47.4 \%)$ suffering from concomitant carcinomatous meningitis were treated with intrathecal triple therapy [32]. Surgical tumor resection was not performed in any case.

\section{Outcome and survival}

MS occurred within a median of 425 days after HSCT. 18/ 19 patients died: 13/19 (68.4\%) patients from progression of MS or the underlying systemic disease and 5/19 (26.3\%) patients from severe infections.

Median $\mathrm{OS}^{\mathrm{HSCT}}$ was 641 days and $\mathrm{OS}^{\mathrm{MS}} 234$ days (Fig. 1). OS ${ }^{\mathrm{MS}}$ did not differ significantly in patients suffering from SAML compared to primary AML (not shown). Therefore, the entities AML and sAML were combined to compare the frequency of MS development when treated with MAC and lower intensity conditioning (LIC; RIC and NMAC), revealing significantly more MS in the LIC-treated AML and sAML cohort $(P=0.024$, unpaired t-test with Welch's correction, not shown).

Survival probabilities were significantly better in GvHD patients (MSFS $P=0.048$, $^{\mathrm{O} S}{ }^{\mathrm{HSCT}} P=0.032$, not shown; Log-rank). Additionally, patients with non-monoblastic differentiation had a significantly longer survival (MSFS

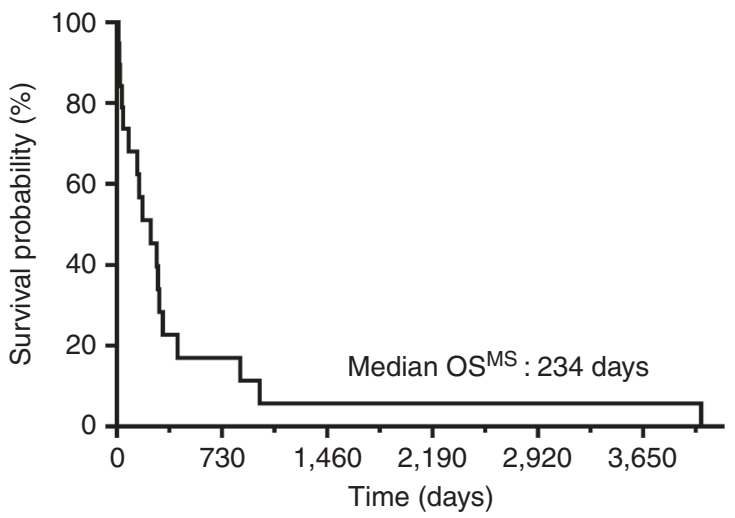

Fig. 1 Kaplan-Meier survival curve showing overall survival from MS onset $\left(\mathbf{O S}^{\mathrm{MS}}\right)$ of all 19 patients. Median $\mathrm{OS}^{\mathrm{MS}}$ was 234 days.

$P=0.022, \mathrm{OS}^{\mathrm{HSCT}} P=0.021, \mathrm{OS}^{\mathrm{MS}} P=0.071$, not shown; Log-rank). Other variables being analyzed, such as sex, risk stratification according to ELN-criteria [20], isolated EM versus systemic relapse and MS with regard to affection of CNS did not affect OS or MSFS. Notably, affection of CNS did not divide patients in to distinct groups.

\section{Discussion and conclusion}

Isolated EM relapse after HSCT is a rare event, with incidence rates between $0.65-30 \%$ [13, 33-36] and a median MSFS of 210 days [6, 34]. Three-fourths of EM relapses happened within the first 2 years after HSCT [7]. In the largest series of isolated MS after HSCT, OS at 5 years was $48 \%$ and disease-free survival $36 \%$ [37]. Although the incidence rate of MS of 16/307 (5.21\%) within 18 years after HSCT and median OS $^{\mathrm{MS}}$ with 234 days is in line with previous reports, a median $\mathrm{OS}^{\mathrm{HSCT}}$ of 641 days is not that adverse [36, 38-41]. With the exception of three patients, the reported results confirm the finding that only patients relapsing within 1 year after HSCT suffered from concomitant EM and systemic relapse [13, 42]. However, as $8-20 \%$ and even up to $95 \%$ of patients progress from isolated EM to systemic relapse after HSCT, the rate at our clinic was low $[33,35]$. Nonetheless, relapse is a major cause of mortality $[43,44]$.

The engrafting immune system after HSCT is held to be responsible for inducing remission and long-term survival by eliminating the malignant cells. Alloreactive $\mathrm{T}$ cells are thought to be responsible not only for the graft-versusleukemia $(\mathrm{GvL})$ effect but also for mediating GvHD [43, 44].

Previous cGvHD was associated with better OS [10] and aGvHD with better relapse-free survival [13]. Thus, OS ${ }^{\text {HSCT }}$ and MSFS are higher in GvHD patients, compared to those without GvHD at all. However, in contrast to a previous study [42], the association between cGvHD before relapse 
and improved OS after relapse could not be confirmed. Since nearly half of the patients $(9 / 19 ; 47.4 \%)$ with EM relapse did not develop systemic relapse, the relevance of GvL must be stressed.

Beyond GvHD, further factors have been identified as being associated with EM relapse after HSCT, including donor lymphocyte infusion, younger age, EM manifestations before HSCT, advanced disease at HSCT, unfavorable cytogenetics, and M4/M5 subtypes according to FAB classification [13, 35]. No association between genetic risk stratification according to ELN-criteria [20] and MSFS and OS could be confirmed. Nevertheless, survival was significantly better for patients with non-monoblastic differentiation. In addition, the intensity of conditioning seems to play a role in the onset of EM relapse after HSCT. An association between EM relapse and busulfan-based regimens was observed $[7,45]$. Taking into account that only two patients developed MS after MAC in contrast to all other patients after LIC $(P=0.024$, unpaired t-test, with Welch's correction, not shown), suggests that LIC may increase the risk for EM relapse.

Notably, except for one patient (1/9) whose clinical condition deteriorated quickly before diagnostic imaging, we were able to prove that carcinomatous meningitis was concomitant to solid involvement of the CNS in every single case. Therefore extensive and enlarged diagnostic imaging of the whole CNS is recommended as part of the diagnostic workup in order to reveal solid MS manifestations.

Although the armamentarium for the treatment of isolated MS has been widened since the introduction of targeted therapies, one should keep in mind that MS represents part of a systemic disease and is believed to progress rapidly to systemic relapse without therapy $[9,11]$. Therefore, systemic chemotherapy may be an appropriate therapeutic approach [34, 46]. Nevertheless, the optimal therapy post-HSCT is a matter of debate. The choice of therapy depends on the time from transplant to MS onset, the patients' general health condition, the chimerism, and the presence of GvHD [10]. As a less effective GvL-effect is considered to be causative for the formation of MS, donor lymphocyte infusion and tapering of immunosuppression are recommended [6-8, 10]. Hypomethylating agents might enhance GvL by increasing HLA and tumor-associated antigen expression $[13,35,47]$. Another therapeutic option is the application of gemtuzumab ozogamizin [13, 35]. Whenever suitable, use of targeted therapies, i.e. tyrosine kinase inhibitors for FLT3-ITD, is recommended [11, 47]. In addition, inhibition of CTL-4 may prevent immune escape and can result in complete response of MS [48]. In case of rapid tumor growth, surgery or palliative radiotherapy can be considered $[9,11]$. A combinational approach seems to be advantageous $[6,7,9]$.

Although, HSCT is a feasible option for the treatment of isolated or leukemic MS, the impact of a secondary allogeneic HSCT, remains unclear [10, 35, 37, 46, 49].

In this reported cohort, the majority of patients received local or subcutaneous applicable anti-tumor therapy, e.g. epigenetic drugs, to facilitate outpatient treatment in a predominantly palliative situation. Patient \#1 underscores particularly well the importance of a wise choice of the therapeutic strategy that was most likely the cause of this patient's over 11-year-suvival with MS (see Table 1, Supplementary Materials and Supplementary Fig. S1; additional information concerning patient \#3, \#5 and \#11 is also provided within the Supplementary Materials and Supplementary Figs. S2-S4). Although this is an individual case, it emphasizes that despite the very poor prognosis recurrent isolated MS can result in long-term survival [33]. Au and colleagues even reported prolonged survival in up to a third of all patients [40].

The limitations of the study are the retrospective design and the small number of patients. However, it demonstrates that (a) the intensity of conditioning may have an impact on the onset of MS and that (b) a choosing treatment wisely can lead to a prolonged OS in an utmost dismal situation. Future studies are necessary to further elucidate the pathophysiological interconnections, discover novel therapeutic agents and finally improve the outcome of HSCT recipients with MS.

\section{Data availability}

The authors confirm that the data supporting the findings of this study are available within the article.

Funding This work was supported by institutional work funding. Open access funding provided by Projekt DEAL.

Author contributions All authors read and approved the final manuscript. $\mathrm{CW}, \mathrm{FH}, \mathrm{JF}$ and $\mathrm{IH}$ collected and provided data on the inpatient and outpatient treatment of the cases presented. TF provided radiological imagery. FH, JF and IH analyzed data, compiled diagnostic data and wrote the manuscript.

\section{Compliance with ethical standards}

Conflict of interest JF received travel grants from GILEAD Sciences $\mathrm{GmbH}$, Planegg, Germany. IH received travel grants from medac $\mathrm{GmbH}$, Wedel, Germany and honoraria from Novartis, Basel, Switzerland. The other authors do not declare any conflicts of interest.

Ethical approval Based on Thuringian law and our clinical Ethics Committee, reports providing routinely collected data do not need approval by the Ethics Committee. The authors have no ethical conflicts to disclose. 
Informed consent Written informed consent was obtained from our patients for publication in this report.

Publisher's note Springer Nature remains neutral with regard to jurisdictional claims in published maps and institutional affiliations.

Open Access This article is licensed under a Creative Commons Attribution 4.0 International License, which permits use, sharing, adaptation, distribution and reproduction in any medium or format, as long as you give appropriate credit to the original author(s) and the source, provide a link to the Creative Commons license, and indicate if changes were made. The images or other third party material in this article are included in the article's Creative Commons license, unless indicated otherwise in a credit line to the material. If material is not included in the article's Creative Commons license and your intended use is not permitted by statutory regulation or exceeds the permitted use, you will need to obtain permission directly from the copyright holder. To view a copy of this license, visit http://creativecommons. org/licenses/by/4.0/.

\section{References}

1. Vardiman JW, Thiele J, Arber DA, Brunning RD, Borowitz MJ, Porwit A, et al. The 2008 revision of the World Health Organization (WHO) classification of myeloid neoplasms and acute leukemia: rationale and important changes. Blood. 2009;114:937-51. https://doi.org/10.1182/blood-2009-03-209262.

2. Pileri SA, Ascani S, Cox MC, Campidelli C, Bacci F, Piccioli M, et al. Myeloid sarcoma: clinico-pathologic, phenotypic and cytogenetic analysis of 92 adult patients. Leukemia. 2007;21:340-50. https://doi.org/10.1038/sj.leu.2404491.

3. Arber DA, Orazi A, Hasserjian R, Thiele J, Borowitz MJ, Le Beau MM, et al. The 2016 revision to the World Health Organization classification of myeloid neoplasms and acute leukemia. Blood. 2016;127:2391-405. https://doi.org/10.1182/blood-201603-643544.

4. Campidelli C, Agostinelli C, Stitson R, Pileri SA. Myeloid sarcoma: extramedullary manifestation of myeloid disorders. Am J Clin Pathol. 2009;132:426-37. https://doi.org/10.1309/AJCP1ZA 7HYZKAZHS.

5. Wilson CS, Medeiros LJ. Extramedullary manifestations of myeloid neoplasms. Am J Clin Pathol. 2015;144:219-39. https:// doi.org/10.1309/AJCPO58YWIBUBESX.

6. Xie N, Zhou J, Zhang Y, Yu F, Song Y. Extramedullary relapse of leukemia after allogeneic hematopoietic stem cell transplantation: a retrospective study. Med (Baltim). 2019;98:e15584. https://doi. org/10.1097/MD.0000000000015584.

7. Cunningham I. Extramedullary sites of leukemia relapse after transplant. Leuk Lymphoma. 2006;47:1754-67. https://doi.org/10. 1080/10428190600632857.

8. Lee KH, Lee JH, Kim S, Lee JS, Kim SH, Kim WK. High frequency of extramedullary relapse of acute leukemia after allogeneic bone marrow transplantation. Bone Marrow Transpl. 2000;26:147-52. https://doi.org/10.1038/sj.bmt.1702488.

9. Magdy M, Abdel Karim N, Eldessouki I, Gaber O, Rahouma M, Ghareeb M. Myeloid sarcoma. Oncol Res Treat. 2019;42:224-9. https://doi.org/10.1159/000497210.

10. Solh M, Solomon S, Morris L, Holland K, Bashey A. Extramedullary acute myelogenous leukemia. Blood Rev. 2016;30: 333-9. https://doi.org/10.1016/j.blre.2016.04.001.

11. Almond LM, Charalampakis M, Ford SJ, Gourevitch D, Desai A. Myeloid sarcoma: presentation, diagnosis, and treatment. Clin Lymphoma Myeloma Leuk. 2017;17:263-7. https://doi.org/10. 1016/j.clml.2017.02.027.
12. Stolzel F, Luer T, Lock S, Parmentier S, Kuithan F, Kramer M. et al. The prevalence of extramedullary acute myeloid leukemia detected by 18FDG-PET/CT: final results from the Prospective PETAML Trial. Haematologica. 2019. https://doi.org/10.3324/ha ematol.2019.223032.

13. Yoshihara S, Ando T, Ogawa $\mathrm{H}$. Extramedullary relapse of acute myeloid leukemia after allogeneic hematopoietic stem cell transplantation: an easily overlooked but significant pattern of relapse. Biol Blood Marrow Transpl. 2012;18:1800-7. https://doi.org/10. 1016/j.bbmt.2012.05.010.

14. Kroger N, Bornhauser M, Ehninger G, Schwerdtfeger R, Biersack $\mathrm{H}$, Sayer $\mathrm{HG}$, et al. Allogeneic stem cell transplantation after a fludarabine/busulfan-based reduced-intensity conditioning in patients with myelodysplastic syndrome or secondary acute myeloid leukemia. Ann Hematol. 2003;82:336-42. https://doi.org/ 10.1007/s00277-003-0654-9.

15. Casper J, Holowiecki J, Trenschel R, Wandt H, Schaefer-Eckart $\mathrm{K}$, Ruutu T, et al. Allogeneic hematopoietic SCT in patients with AML following treosulfan/fludarabine conditioning. Bone Marrow Transpl. 2012;47:1171-7. https://doi.org/10.1038/bmt. 2011.242.

16. Hilgendorf I, Winkelmann N, Frietsch JJ, Hunstig F, Schnetzke U, Scholl S, et al. Treosulfan, fludarabine and cytarabine as conditioning before allogeneic hematopoietic stem cell transplantation. Blood. 2018;132:5702-5702. https://doi.org/10.1182/blood2018-99-118259.

17. Jethava YS, Sica S, Savani B, Socola F, Jagasia M, Mohty M, et al. Conditioning regimens for allogeneic hematopoietic stem cell transplants in acute myeloid leukemia. Bone Marrow Transpl. 2017;52:1504-11. https://doi.org/10.1038/bmt.2017.83.

18. Niederwieser D, Maris M, Shizuru JA, Petersdorf E, Hegenbart U, Sandmaier BM, et al. Low-dose total body irradiation (TBI) and fludarabine followed by hematopoietic cell transplantation (HCT) from HLA-matched or mismatched unrelated donors and postgrafting immunosuppression with cyclosporine and mycophenolate mofetil (MMF) can induce durable complete chimerism and sustained remissions in patients with hematological diseases. Blood. 2003;101:1620-9. https://doi.org/10.1182/blood-2002-051340.

19. Mohty M, Malard F, Blaise D, Milpied N, Socie G, Huynh A, et al. Sequential regimen of clofarabine, cytarabine and reduced intensity conditioning (RIC) prior to allogeneic stem cell transplantation (allo-SCT) for acute myeloid leukemia (AML) in primary treatment failure. Blood. 2014;124:1228-1228. https://doi. org/10.1182/blood.V124.21.1228.1228.

20. Dohner H, Estey E, Grimwade D, Amadori S, Appelbaum FR, Buchner T, et al. Diagnosis and management of AML in adults: 2017 ELN recommendations from an international expert panel. Blood. 2017;129:424-47. https://doi.org/10.1182/blood-2016-08733196.

21. Fleischmann T, Hilgendorf I, Franiel T. Das Myelosarkom der Hypophyse - eine Rarität eines isolierten Rezidivs einer akuten myeloischen Leukämie. Rofo. 2018;190:273-4. https://doi.org/10. 1055/s-0043-122080.

22. Glucksberg H, Storb R, Fefer A, Buckner CD, Neiman PE, Clift RA, et al. Clinical manifestations of graft-versus-host disease in human recipients of marrow from HL-A-matched sibling donors. Transplantation. 1974;18:295-304. https://doi.org/10.1097/ 00007890-197410000-00001.

23. Filipovich AH, Weisdorf D, Pavletic S, Socie G, Wingard JR, Lee SJ, et al. National Institutes of Health consensus development project on criteria for clinical trials in chronic graft-versus-host disease: I. Diagnosis and staging working group report. Biol Blood Marrow Transpl. 2005;11:945-56. https://doi.org/10.1016/ j.bbmt.2005.09.004. 
24. Hanel M, Friedrichsen K, Hanel A, Herbst R, Morgner A, Neser $\mathrm{S}$, et al. Mito-flag as salvage therapy for relapsed and refractory acute myeloid leukemia. Onkologie. 2001;24:356-60. https://doi. org/10.1159/000055107.

25. Buchner T, Schlenk RF, Schaich M, Dohner K, Krahl R, Krauter J, et al. Acute Myeloid Leukemia (AML): different treatment strategies versus a common standard arm-combined prospective analysis by the German AML Intergroup. J Clin Oncol. 2012;30:3604-10. https://doi.org/10.1200/JCO.2012.42.2907.

26. Schroeder T, Rautenberg C, Haas R, Germing U, Kobbe G. Hypomethylating agents for treatment and prevention of relapse after allogeneic blood stem cell transplantation. Int $\mathrm{J}$ Hematol. 2018;107:138-50. https://doi.org/10.1007/s12185-017-2364-4.

27. Wolleschak D, Schalk E, Krogel C, Schnoeder TM, Luehr H, Jentsch-Ullrich $\mathrm{K}$, et al. Rapid induction of complete molecular remission by sequential therapy with LDAC and sorafenib in FLT3-ITD-positive patients unfit for intensive treatment: two cases and review of the literature. J Hematol Oncol. 2013;6:39. https://doi.org/10.1186/1756-8722-6-39.

28. Cortes JE, Khaled S, Martinelli G, Perl AE, Ganguly S, Russell N, et al. Quizartinib versus salvage chemotherapy in relapsed or refractory FLT3-ITD acute myeloid leukaemia (QuANTUM-R): a multicentre, randomised, controlled, open-label, phase 3 trial. Lancet Oncol. 2019;20:984-97. https://doi.org/10.1016/S14702045(19)30150-0.

29. Funke I, Wiesneth M, Platow S, Kubanek B. Palliative cytoreduction in refractory acute leukemia: a retrospective study of 57 adult patients. Ann Hematol. 2000;79:132-7. https://doi.org/10. 1007/s002770050568.

30. Sperr WR, Hauswirth AW, Wimazal F, Knobl P, Geissler K, Valent P. Treatment concepts for elderly patients with acute myeloid leukemia. Wien Klin Wochenschr. 2003;115:505-14. https://doi.org/10.1007/BF03041034.

31. Burnett AK, Milligan D, Prentice AG, Goldstone AH, McMullin MF, Hills RK, et al. A comparison of low-dose cytarabine and hydroxyurea with or without all-trans retinoic acid for acute myeloid leukemia and high-risk myelodysplastic syndrome in patients not considered fit for intensive treatment. Cancer. 2007;109:1114-24. https://doi.org/10.1002/cncr.22496.

32. Alakel N, Stolzel F, Mohr B, Kramer M, Oelschlagel U, Rollig C, et al. Symptomatic central nervous system involvement in adult patients with acute myeloid leukemia. Cancer Manag Res. 2017;9:97-102. https://doi.org/10.2147/CMAR.S125259.

33. Koc Y, Miller KB, Schenkein DP, Daoust P, Sprague K, Berkman E. Extramedullary tumors of myeloid blasts in adults as a pattern of relapse following allogeneic bone marrow transplantation. Cancer. 1999;85:608-15. https://doi.org/10.1002/(Sici)1097-0142 (19990201)85:3<608::Aid-Cncr11>3.0.Co;2-5.

34. Yuda S, Fuji S, Onishi A, Tanaka T, Inamoto Y, Kurosawa S, et al. Extramedullary relapse of acute myelogenous leukemia after allogeneic hematopoietic stem cell transplantation. Biol Blood Marrow Transpl. 2019;25:1152-7. https://doi.org/10.1016/j.bbmt. 2019.01.011.

35. Clark WB, Strickland SA, Barrett AJ, Savani BN. Extramedullary relapses after allogeneic stem cell transplantation for acute myeloid leukemia and myelodysplastic syndrome. Haematologica. 2010;95:860-3. https://doi.org/10.3324/haematol.2010.025890.

36. Curley C, Durrant S, Kennedy GA. Is extramedullary relapse of acute myeloid leukemia after allogeneic hematopoietic stem cell transplantation associated with improved survival? Asia Pac J Clin Oncol. 2013;9:285-9. https://doi.org/10.1111/ajco.12058.

37. Chevallier P, Mohty M, Lioure B, Michel G, Contentin N, Deconinck E, et al. Allogeneic hematopoietic stem-cell transplantation for myeloid sarcoma: a retrospective study from the SFGM-TC. J Clin Oncol. 2008;26:4940-3. https://doi.org/10. 1200/JCO.2007.15.6315.
38. Rautenberg C, Germing U, Haas R, Kobbe G, Schroeder T. Relapse of acute myeloid leukemia after allogeneic stem cell transplantation: prevention, detection, and treatment. Int J Mol Sci. 2019;20:228. https://doi.org/10.3390/ijms20010228.

39. Massenkeil G, Nagy M, Neuburger S, Tamm I, Lutz C, le Coutre $\mathrm{P}$, et al. Survival after reduced-intensity conditioning is not inferior to standard high-dose conditioning before allogeneic haematopoietic cell transplantation in acute leukaemias. Bone Marrow Transpl. 2005;36:683-9. https://doi.org/10.1038/sj.bmt. 1705123

40. Au WY, Kwong YL, Lie AK, Ma SK, Liang R. Extra-medullary relapse of leukemia following allogeneic bone marrow transplantation. Hematol Oncol. 1999;17:45-52. https://doi.org/10. 1002/(sici)1099-1069(199906)17:2<45::aid-hon641>3.0.co;2-6.

41. Tsirigotis P, Byrne M, Schmid C, Baron F, Ciceri F, Esteve J, et al. Relapse of AML after hematopoietic stem cell transplantation: methods of monitoring and preventive strategies. A review from the ALWP of the EBMT. Bone Marrow Transpl. 2016;51:1431-8. https://doi.org/10.1038/bmt.2016.167.

42. Solh M, DeFor TE, Weisdorf DJ, Kaufman DS. Extramedullary relapse of acute myelogenous leukemia after allogeneic hematopoietic stem cell transplantation: better prognosis than systemic relapse. Biol Blood Marrow Transpl. 2012;18:106-12. https://doi. org/10.1016/j.bbmt.2011.05.023.

43. Dickinson AM, Norden J, Li S, Hromadnikova I, Schmid C, Schmetzer H, et al. Graft-versus-Leukemia Effect Following Hematopoietic Stem Cell Transplantation for Leukemia. Front Immunol. 2017;8:496. https://doi.org/10.3389/fimmu.2017.00496.

44. Cassady K, Martin PJ, Zeng D. Regulation of GVHD and GVL activity via PD-L1 interaction with PD-1 and CD80. Front Immunol. 2018;9:3061. https://doi.org/10.3389/fimmu. 2018.03061.

45. Simpson DR, Nevill TJ, Shepherd JD, Fung HC, Horsman DE, Nantel $\mathrm{SH}$, et al. High incidence of extramedullary relapse of AML after busulfan/cyclophosphamide conditioning and allogeneic stem cell transplantation. Bone Marrow Transpl. 1998;22:259-64. https://doi.org/10.1038/sj.bmt.1701319.

46. Chevallier P, Labopin M, Cornelissen J, Socie G, Rocha V, Mohty $\mathrm{M}$, et al. Allogeneic hematopoietic stem cell transplantation for isolated and leukemic myeloid sarcoma in adults: a report from the Acute Leukemia Working Party of the European group for Blood and Marrow Transplantation. Haematologica. 2011;96:1391-4. https://doi.org/10.3324/haematol.2011.041418.

47. Bernasconi P, Borsani O. Immune escape after hematopoietic stem cell transplantation (HSCT): from mechanisms to novel therapies. Cancers (Basel) 2019; 12. https://doi.org/10.3390/ca ncers 12010069.

48. Davids MS, Kim HT, Bachireddy P, Costello C, Liguori R, Savell A, et al. Ipilimumab for patients with relapse after allogeneic transplantation. N. Engl J Med. 2016;375:143-53. https://doi.org/ 10.1056/NEJMoa1601202.

49. Lazzarotto D, Candoni A, Fili C, Forghieri F, Pagano L, Busca A, et al. Clinical outcome of myeloid sarcoma in adult patients and effect of allogeneic stem cell transplantation. Results a Multicent Surv Leuk Res. 2017;53:74-81. https://doi.org/10.1016/j.leukres. 2016.12.003.

50. Sorror ML, Maris MB, Storb R, Baron F, Sandmaier BM, Maloney DG, et al. Hematopoietic cell transplantation (HCT)-specific comorbidity index: a new tool for risk assessment before allogeneic HCT. Blood. 2005;106:2912-9. https://doi.org/10.1182/ blood-2005-05-2004.

51. Johansen S, Kollsete Gjelberg $\mathrm{H}$, Ahmed AB, Bruserud $\mathrm{O}$, Reikvam H. Myeloid sarcoma after allogenic stem cell transplantation for acute myeloid leukemia: successful consolidation treatment approaches in two patients. Case Rep. Oncol Med. 2018;2018:7697283. https://doi.org/10.1155/2018/7697283. 
52. Cho SF, Liu TC, Chang CS. Isolated central nervous system relapse presenting as myeloid sarcoma of acute myeloid leukemia after allogeneic peripheral blood stem cell transplantation. Ann Hematol. 2013;92:133-5. https://doi.org/10.1007/s00277-012-1540-0.

53. Lin HW, Shih SR, Yao M, Huang TS. Relapse of acute myeloid leukemia at the pituitary gland: a case report and review of literature. Endocr Pathol. 2012;23:172-6. https://doi.org/10.1007/ s12022-012-9203-1.

54. Muller CI, Engelhardt M, Laubenberger J, Kunzmann R, Engelhardt R, Lubbert M. Myelodysplastic syndrome in transformation to acute myeloid leukemia presenting with diabetes insipidus: due to pituitary infiltration association with abnormalities of chromosomes 3 and 7. Eur J Haematol. 2002;69:115-9. https://doi.org/10. 1034/j.1600-0609.2002.02763.x.

55. Kurtz JE, Andres E, Veillon F, Maloisel F, Gentine A, Herbrecht R, et al. Hearing loss due to acute leukemia. Am J Med. 2000;109:509-10. https://doi.org/10.1016/S0002-9343(00)00563-5.

56. Khan AA, Nazir S, Ahmed A. Relapse of acute myeloid leukemia presenting as acute otitis media. QJM. 2010;103:533-4. https:// doi.org/10.1093/qjmed/hcp138. 